\title{
Conceptual Design of a 10 MW Multipurpose Research Reactor Using VVR-KN Fuel
}

\author{
Nhi-Dien Nguyen $\mathbb{D}^{1},{ }^{1}$ Kien-Cuong Nguyen, ${ }^{1}$ Ton-Nghiem Huynh, ${ }^{1}$ Doan-Hai-Dang Vo, ${ }^{1}$ \\ and Hoai-Nam Tran iD 2,3 \\ ${ }^{1}$ Dalat Nuclear Research Institute, VINATOM, 01 Nguyen Tu Luc, Dalat, Lamdong 670000, Vietnam \\ ${ }^{2}$ Institute of Fundamental and Applied Sciences, Duy Tan University, Ho Chi Minh City 700000, Vietnam \\ ${ }^{3}$ Faculty of Natural Sciences, Duy Tan University, Da Nang 550000, Vietnam
}

Correspondence should be addressed to Nhi-Dien Nguyen; diennn.re@dnri.vn and Hoai-Nam Tran; tranhoainam4@dtu.edu.vn

Received 30 January 2020; Accepted 15 May 2020; Published 25 August 2020

Academic Editor: Leon Cizelj

Copyright (c) 2020 Nhi-Dien Nguyen et al. This is an open access article distributed under the Creative Commons Attribution License, which permits unrestricted use, distribution, and reproduction in any medium, provided the original work is properly cited.

\begin{abstract}
The paper presents a conceptual design of a $10 \mathrm{MW}$ multipurpose nuclear research reactor (MPRR) loaded with the low-enriched uranium (LEU) VVR-KN fuel type. Neutronics and burnup calculations have been performed using the REBUS-MCNP6 linkage system code and the ENDF/B-VII.0 data library. The core consists of 36 fuel assemblies: 27 standard fuel assemblies and 9 control fuel assemblies with the uranium density of $2.8 \mathrm{gU} / \mathrm{cm}^{3}$ and the ${ }^{235} \mathrm{U}$ enrichment of $19.75 \mathrm{wt} . \%$. The cycle length of the core is 86 effective full-power days with the excess reactivity of 9600 and $1039 \mathrm{pcm}$ at the beginning of cycle and the end of cycle, respectively. The highest power rate and the highest discharged burnup of fuel assembly are $393.49 \mathrm{~kW}$ and $56.74 \%$ loss of ${ }^{235} \mathrm{U}$, respectively. Thermal hydraulics analysis has also been conducted using the PLTEMP4.2 code for evaluating the safety parameters at a steady state of the hottest channel. The maximum temperatures of coolant and fuel cladding are $66.0^{\circ} \mathrm{C}$ and $83.0^{\circ} \mathrm{C}$, respectively. This value is lower than the design limit of $98^{\circ} \mathrm{C}$ for cladding temperature. Thermal fluxes at the vertical irradiation channels and the horizontal beam ports have been evaluated. The maximum thermal fluxes of $2.5 \times 10^{14}$ and $8.9 \times 10^{13} \mathrm{n} \cdot \mathrm{cm}^{-2} \cdot \mathrm{s}^{-1}$ are found at the neutron trap and the beryllium reflector, respectively.
\end{abstract}

\section{Introduction}

Research reactor is an important tool for supporting research and development in a wide range of scientific aspects such as neutron scattering, neutron activation analysis, material testing, medicine application, biological science, and education and training $[1,2]$. The $500 \mathrm{~kW}$ Dalat Nuclear Research Reactor (DNRR) (located in Dalat, Vietnam) is currently a unique research reactor in the country. The DNRR was reconstructed and upgraded from a $250 \mathrm{~kW}$ TRIGA Mark II reactor in the early 1980s. The core is loaded with Russian VVR-M2 fuel. The operation of the DNRR is mainly for radioisotope production (RI), neutron activation analysis (NAA), basic and applied researches, and training $[3,4]$. However, due to the limitation of power and experimental facilities, the DNRR cannot meet the increasing demands of radioisotope production for medical and industrial applications, facilities for nuclear physics experiments, and support to nuclear power development in the future. The DNRR has been operational safely for about 35 years, and it is planned to continue the reactor operation for about a decade. Then, it is highly desirable to replace the DNRR by a new research reactor with a higher power output. For that purpose, the country is planning to build a new multipurpose research reactor (MPRR) with the power of $10 \mathrm{MW}$. In addition to traditional applications, such as RI, NAA, and neutron imaging (NI), other advanced researches and applications, such as neutron transmutation doping of silicon (NTD), material science research and characterization by neutron scattering, and production of special isotopes using high neutron fluxes and so forth are being considered with the new MPRR. For most of the 
applications, high thermal neutron fluxes and high irradiation volumes are desirable, for example, thermal flux higher than $2.0 \times 10^{14} \mathrm{n} \cdot \mathrm{cm}^{-2} \cdot \mathrm{s}^{-1}$, though there exist a number of constraints and difficulties to achieve this goal $[5,6]$.

A number of MPRRs with the power output greater than $10 \mathrm{MW}$ currently in operation, under construction, and planned were reviewed $[6,7]$. Most of the MPRRs use platetype material test reactor (MTR) fuel and heavy water as a reflector. The IRT-1 reactor in Libya is the only one using tube-type fuel. In the last 30 years, the MTR fuel with the density of $4.8 \mathrm{gU} / \mathrm{cm}^{3}$ and burnable poison integrated fuel elements was mostly used in the designs of high-performance MPRRs. The KJRR reactor in Korea is designed using the MTR fuel with a high density of $8.0 \mathrm{gU} / \mathrm{cm}^{3}$ and beryllium and graphite reflectors [8]. The plate-type fuel with the uranium density of $3 \mathrm{gU} / \mathrm{cm}^{3}$ was also used in the MPRR design with the power of $20 \mathrm{MW}$ for achieving high neutron fluxes at irradiation channels [5]. Several designs of MPRRs include the OPAL reactor $(20 \mathrm{MW})$ in Australia $[9,10]$, the CARR reactor $(60 \mathrm{MW})$ in China, the RA-10 reactor (30 MW) in Argentina [11], the HFIR reactor (85 MW) in USA, the FRM-II reactor (20 MW) in Germany [12], the HANARO reactor $(30 \mathrm{MW})$ in Korea [13, 14], JRR-3M (20 MW) in Japan, the RMB reactor (30 MW) in Brazil [15], and the JRTR reactor (5 MW) in Jordan [16]. A comparison among several MPRRs shows that the FRM-II reactor achieves the highest thermal flux per unit power with a maximum thermal neutron flux of $8 \times 10^{14} \mathrm{n} \cdot \mathrm{cm}^{-2} \cdot \mathrm{s}^{-1}$ [6]. The OPAL reactor achieves the maximum thermal flux of $3 \times 10^{14} \mathrm{n} \cdot \mathrm{cm}^{-2} \cdot \mathrm{s}^{-1}$, allowing various applications of cold, thermal, and hot neutron beams, radioisotopes production, and silicon doping. Based on the capabilities of the OPAL reactor and the high thermal flux of the FRM-II reactor, an innovative design of a compact MPRR core with a power level of $10 \mathrm{MW}$ and maximum thermal flux of $5 \times 10^{14} \mathrm{n} \cdot \mathrm{cm}^{-2} \cdot \mathrm{s}^{-1}$ was investigated [6].

In the present work, a conceptual design of $10 \mathrm{MW}$ MPRR core loaded with the Russian tube-type VVR-KN fuel assemblies has been conducted. Neutronics and burnup calculations have been performed using the REBUS-MCNP6 linkage system code. The VVR-KN fuel assembly contains low enriched uranium fuel with the density of $2.8 \mathrm{gU} / \mathrm{cm}^{3}$. The active core is surrounded by a beryllium reflector to attain high thermal neutron fluxes and high performance of irradiation channels. In the design process, the numbers of fuel assemblies and control rods and their arrangement in the core are determined for obtaining enough excess reactivity during the core operation for compensating a number of irradiation applications, while ensuring safety requirements. Thus, neutronic characteristics of the MPRR core including burnup performance, power distribution and power peaking factor, control rod worths, reactivity coefficients, sizes and types of irradiation holes for a variety of applications, neutron fluxes at irradiation channels, and so forth have been investigated. One of the design objectives is to attain high thermal neutron fluxes in the core and irradiation channels with maximum thermal neutron fluxes at the core center and at the beryllium reflector of about $2.0-3.0 \times 10^{14}$ and $0.5-1.0 \times 10^{14} \mathrm{n} \cdot \mathrm{cm}^{-2} \cdot \mathrm{s}^{-1}$, respectively.
Thermal hydraulics analysis has also been performed using the PLTEMP4.2 code to evaluate the safety parameters at a steady state of the MPRR core.

The paper is organized as follows. Section 2 presents a brief description of the VVR-KN fuel assembly and the design targets of the MPRR core. Section 3 describes the calculation methods using the REBUS-MCNP6 linkage system code and the PLTEMP4.2 code. The neutronics performance such as burnup reactivity, power distribution, burnup distribution, kinetic parameters, control rod worths, reactivity coefficients, and thermal neutron flux levels of the newly designed MPRR core is presented in Section 4. Section 5 describes the results of thermal hydraulic analysis for obtaining fuel and cladding temperatures and other safetyrelated parameters in the hottest channel of the MPRR core. Finally, concluding remarks are derived in Section 6.

\section{VVR-KN Fuel and MPRR Core Design}

2.1. VVR-KN Fuel. Figure 1 displays the cross-sectional views of two low-enriched uranium (LEU) VVR-KN fuel assemblies (FAs) denoted as FA-1 and FA-2, respectively. FA-1 is a standard fuel assembly consisting of eight concentric tubular fuel elements (FEs). Seven outer FEs of the FA-1 assembly have hexagonal shapes, while the inner FE of the FA-1 assembly is cylindrical. A cylindrical structural tube is located in the center of the FA-1 assembly. FA-2 is a control fuel assembly, which consists of five concentric tubular FEs similar to the outermost FEs of the FA-1 assembly. A cylindrical guide tube for control rod (CR) insertion is located at the center of the FA-2 assembly. The FE has the thickness of $1.6 \mathrm{~mm}$, including the fuel meat with the thickness of $0.7 \mathrm{~mm}$ and two cladding sides with the thickness of $0.45 \mathrm{~mm}$. The fuel meat is ceramic-metal composition of $\mathrm{UO}_{2}-\mathrm{Al}$ with the uranium density of $2.8 \mathrm{gU} / \mathrm{cm}^{3}$. The ${ }^{235} \mathrm{U}$ enrichment is $19.75 \mathrm{wt} \%$. The total ${ }^{235} \mathrm{U}$ amounts in the FA-1 and FA-2 assemblies are $248.2 \mathrm{~g}$ and $197.6 \mathrm{~g}$, respectively. Cladding and structural materials are made of aluminum-alloy SAV-1. Ribs of $1.5 \mathrm{~mm}$ height on the outer surfaces of the FEs are for maintaining the water gap of $2 \mathrm{~mm}$ between the FEs and providing additional stiffening. The active fuel length is $600 \mathrm{~mm}$ with a standard deviation of $2 \mathrm{~mm}$. The total length of neutron absorption $\left(\mathrm{B}_{4} \mathrm{C}\right.$ or stainless steel material) in control rods (CRs) is $680 \mathrm{~mm}$. The follower of the CR is an aluminum rod with the radius of $12.5 \mathrm{~mm}$ and the length of $700 \mathrm{~mm}$. Beryllium rod is solid beryllium with the pitch of $66.3 \mathrm{~mm}$ and the height of $600 \mathrm{~mm}$. The outer dimensions of the beryllium rod are the same as those of the fuel assembly $[17,18]$.

2.2. MPRR Core Design. In the present work, the WWR-K reactor with the power of $6 \mathrm{MW}$ in Kazakhstan is taken as a reference for designing a new MPRR with the power of $10 \mathrm{MW}$ [17]. The reactor type is open swimming pool. The core is cooled and moderated by light water and reflected by beryllium. The reactor core has the height of $180 \mathrm{~cm}$ and the radius of $113.5 \mathrm{~cm}$. Table 1 presents the main design parameters and the design targets of the MPRR core using the 


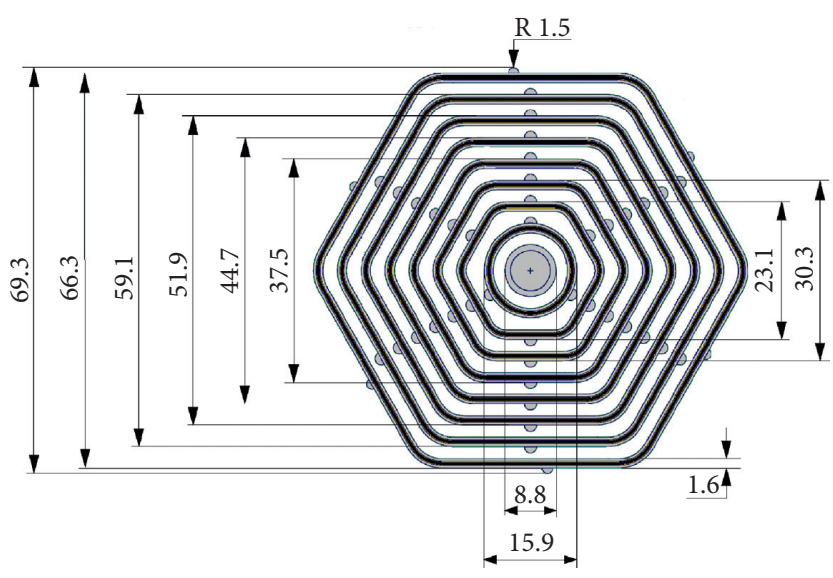

(a)

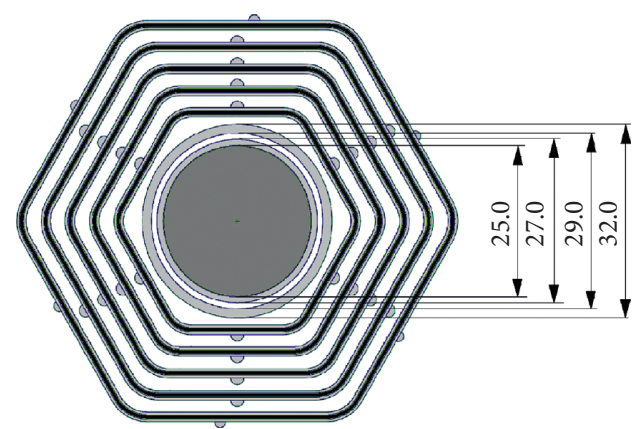

Unit in $\mathrm{mm}$

(b)

FIGURE 1: The VVR-KN fuel assemblies: (a) standard fuel assembly (FA-1) with eight fuel elements and (b) control fuel assembly (FA-2) with five fuel elements.

TABLE 1: Main design parameters and design targets of the MPRR core.

\begin{tabular}{|c|c|}
\hline Technical parameters & Description/value \\
\hline Reactor type & Open swimming pool \\
\hline Thermal power & $10 \mathrm{~W}$ \\
\hline Coolant and moderator & Water \\
\hline Reactor materials & Beryllium \\
\hline Core height $(\mathrm{mm})$ & 600 \\
\hline Fuel type & VVR-KN \\
\hline${ }^{235} \mathrm{U}$ enrichment (wt.\%) & 19.75 \\
\hline Direction of forced convection & Downward \\
\hline Maximum coolant temperature at inlet & $45^{\circ} \mathrm{C}$ \\
\hline Number of horizontal experimental channels & $4-6$ \\
\hline Number of vertical experimental channels & $15-18$ \\
\hline For NTD (8-inch ingots) & $3-4$ \\
\hline For RI (2-3 channels with hydraulic transfer systems) & $10-12$ \\
\hline For NAA with pneumatic transfer systems & $2-3$ \\
\hline Number of control rods & $9-12$ \\
\hline Shim rods (ShR), $\mathrm{B}_{4} \mathrm{C}$ & $6-9$ \\
\hline Safety rods $(\mathrm{SR}), \mathrm{B}_{4} \mathrm{C}$ & $2-3$ \\
\hline Automatic regulating rod (AR), stainless steel & 1 \\
\hline Maximum thermal neutron flux at core center $\left(n \cdot \mathrm{cm}^{-2} \mathrm{~s}^{-1}\right)$ & $2.0-3.0 \times 10^{14}$ \\
\hline Thermal neutron flux at in-core vertical irradiation channels $\left(\mathrm{n} \cdot \mathrm{cm}^{-2} \mathrm{~s}^{-1}\right)$ & Up to $1.5 \times 10^{14}$ \\
\hline Thermal neutron flux in beryllium reflector $\left(\mathrm{n} \cdot \mathrm{cm}^{-2} \mathrm{~s}^{-1}\right)$ & $0.5-1.0 \times 10^{14}$ \\
\hline Thermal neutron flux at irradiation channel for NDT $\left(\mathrm{n} \cdot \mathrm{cm}^{-2} \mathrm{~s}^{-1}\right)$ & $1.0-2.0 \times 10^{13}$ \\
\hline Thermal neutron flux at horizontal beam tubes $\left(\mathrm{n} \cdot \mathrm{cm}^{-2} \mathrm{~s}^{-1}\right)$ & $0.5-1.5 \times 10^{13}$ \\
\hline Average discharged burnup & $50 \%$ \\
\hline Temperature coefficient $(\% \Delta k / k)$ & -0.15 \\
\hline Maximum surface temperature of fuel elements & $<98^{\circ} \mathrm{C}$ \\
\hline Onset nucleate boiling ratio & $>1.3$ \\
\hline
\end{tabular}

VVR-KN FAs [17, 18]. Figure 2 shows the horizontal crosssectional view of the MPRR core. The active core consists of 61 hexagonal cells for containing fuel assemblies, neutron trap, irradiation channels, and beryllium rods. Figure 3 shows the core map with the coordinates of hexagonal cells. In this design, the final core consists of 36 fuel assemblies: 27 assemblies of FA-1 type and 9 assemblies of FA2 type. A neutron trap is located at the core center, and two vertical irradiation channels are located at the peripheral ring. The peripheral ring of the core is loaded with 22 beryllium rods and 2 vertical channels. The beryllium rods provide an additional reflector to the core. It is also possible to create additional irradiation channels by replacing the beryllium rods with vertical channels.

The core is controlled by nine control rods: two safety rods (SR1 and SR2), six shim rods (ShR1-ShR6), and an 


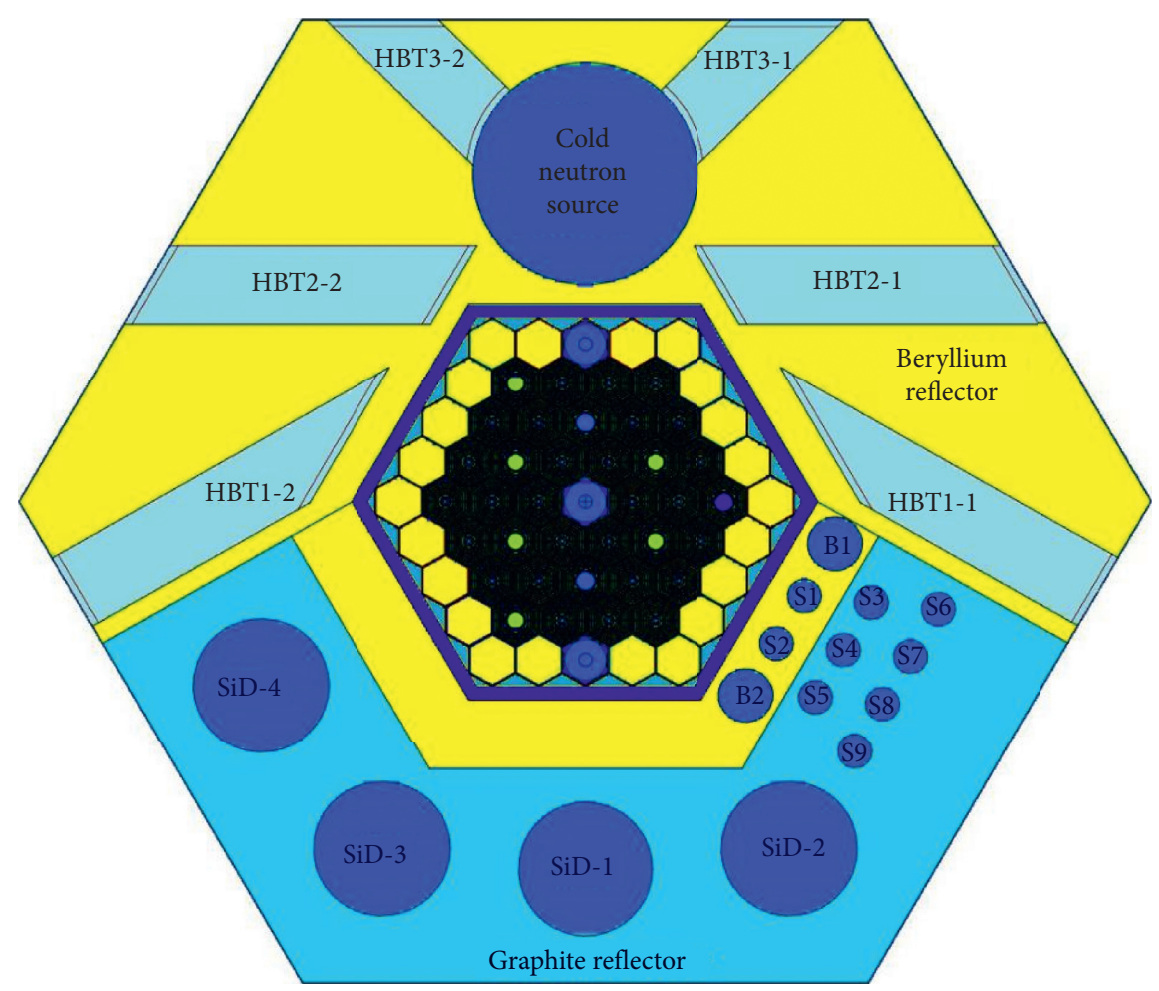

FIGURE 2: Horizontal cross-sectional view of the MPRR core. HBT: horizontal beam tubes; SiD-1 to SiD4: neutron transmutation doping of silicon; S1-S9: small irradiation channels; B1-B2: big irradiation channels.

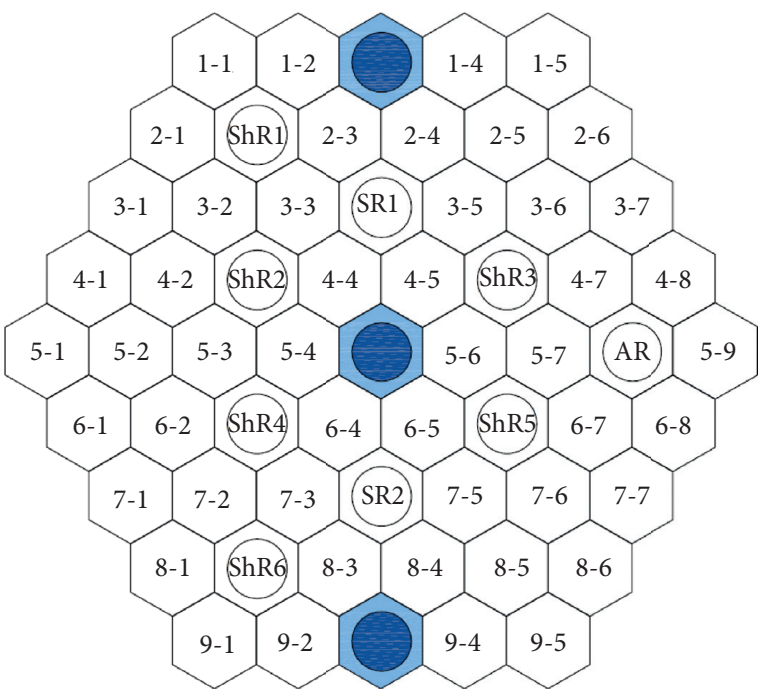

FIGURE 3: The MPRR core map with the hexagonal cell coordinates. SR: safety rod; ShR: shim rod; AR: automatic regulating rod.

automatic regulating rod (AR). The safety rods are normally withdrawn from the core during the reactor operation and are inserted into the core only in the case of reactor shutdown. The insertion of the shim rods is adjusted during the core operation to maintain criticality. The AR rod is partially inserted into the core during the reactor operation. In the case of emergency shutdown, the control rods fall into the core by the gravity. The safety and shim rods use $\mathrm{B}_{4} \mathrm{C}$ as a neutron absorbing material with the density of $1.69 \mathrm{~g} / \mathrm{cm}^{3}$. The AR rod is made of stainless steel with the density of $7.8 \mathrm{~g} / \mathrm{cm}^{3}$ for a smaller reactivity worth.

\section{Calculation Methods}

Neutronic calculations for designing the $10 \mathrm{MW}$ MPRR core have been conducted using the MCNP6 and the ENDF/BVII.0 nuclear data library $[19,20]$. The MCNP code is a general-purpose Monte Carlo radiation-particle transport code developed at Los Alamos National Laboratory [19]. MCNP6 has an ability to describe precisely the complex geometry of the research reactor. Burnup calculations have been performed using the MCNP6-REBUS linkage system code $[21,22]$. The REBUS-PC code was extended to interface with the MCNP code to perform burnup calculations using neutron fluxes and cross sections from the MCNP code [22]. To determine a final core configuration, burnup calculations have been performed for six operating cycles with different core configurations and power levels. In the MCNP6 calculations, the number of neutron history per cycle was chosen as $10^{6}$ with 10 skip cycles and 200 calculated cycles to obtain the statistic error of the effective multiplication factor of about 0.00006 and the error of neutron fluxes within $0.1 \%$.

PLTEMP4.2 is a thermal hydraulics code developed by Los Alamos National Laboratory for analyzing a steady-state flow and temperature solution for a fuel assembly or a reactor core in the subcooled boiling regime [23]. A number of thermal-hydraulic correlations are available in the code to evaluate related safety margins such as onset of nucleate boiling ratio (ONBR), departure from nucleate boiling ratio (DNBR), and onset of flow instability (FI). In the present 
work, the PLTEMP4.2 code has been used to perform thermal hydraulics analysis at a steady state of the newly designed MPRR core for obtaining the safety parameters such as fuel and cladding temperatures, ONBR, and DNBR. The PLTEMP4. 2 code models hexagonal FEs of the FA- 1 and FA-2 assemblies as cylindrical tubes by keeping the equivalent areas of the FEs. The Russian built-in correlation in the PLTEMP4.2 code for the VVR-KN fuel was used for thermal hydraulics analysis of the hottest FA. The heat removal of the reactor is carried out by forced convection with the direction from the core top to the core bottom.

\section{Neutronics Performance of the MPRR Core}

4.1. Burnup Reactivity. The first core configuration was established with 26 FAs (17 FA-1 assemblies and 9 FA-2 assemblies) and the power of $6 \mathrm{MW}$. Burnup calculations were then conducted to establish the next cycle with the increase of power level. After five cycles with the increase of power levels and the number of FAs loaded into the core, a final cycle was obtained. Figure 4 shows the final core configuration of the MPRR with the power of $10 \mathrm{MW}$. Detailed neutronic and burnup calculations have been conducted to determine the neutronic and burnup performance of the MPRR core, such as burnup reactivity, power distribution, burnup distribution, and reactivity coefficients. In the burnup calculations, the beryllium poisoning effect of the beryllium rods and the reflector was also taken into account. The positions of the CRs, especially the shim rods, were adjusted to ensure nearly critical conditions as in the operation conditions of the reactor core. Figure 5 shows the $k_{\text {eff }}$ curve of the MPRR core as a function of effective fullpower days (EFPDs). The operation time of the core with full power is 86 days. The excess reactivity at the BOC and the EOC of the core are 9600 and $1039 \mathrm{pcm}$, respectively. It is worth noticing that the excess reactivity at the BOC is calculated without the xenon poisoning effect, whereas this effect is taken into account in the value at the EOC. The xenon poisoning effect at the BOC is evaluated at about $2970 \mathrm{pcm}$. The excess reactivity at the EOC after a cooling time of about 7 days, when the xenon poisoning effect is ended, is about $3879 \mathrm{pcm}$.

4.2. Power Distribution. Figure 6 displays the radial relative power distribution and the radial power peaking factor (PPF) in the core at the beginning of cycle (BOC). The relative power distribution was obtained by normalizing the power distribution over the core volume. Since the total power is $10 \mathrm{MW}$ and the core consists of $36 \mathrm{FAs}$, the average power rate per assembly is about $277.78 \mathrm{~kW}$. One can see that the radial PPF $\left(F_{x y}\right)$ is 1.415 , which appears at the FA-1 assembly located at cell $8-4$. This PPF corresponds to the power rate of $393.49 \mathrm{~kW}$ of the hottest FA. Since the power distribution of the hottest FA is used as an input for thermal hydraulics and safety analysis, detailed tally option in the MCNP6 has been applied to calculate the axial power profiles of the FEs in the hottest FA. The FEs are numbered from the outer to the inner fuel elements in the assembly, that is, FE-1 is the outermost FE, and FE- 8 is the element at the center of the assembly. Table 2 presents the total power rates of the FEs in the hottest FA. One can see that the power rates and power densities increase from the central tube to the outer tube in the assembly. The highest power rate of $106.21 \mathrm{~kW}$ and the average power density per fuel volume of $1148.46 \mathrm{~W} / \mathrm{cm}^{3}$ are found at the outermost fuel element FE-1 as shown in Table 2. Figure 7 displays the axial power profiles in the FEs of the hottest assembly, that is, the FA-1 assembly located at cell 8-4. It can be seen that the power peak appears at the middle core, and the maximum power density per fuel volume is $1442.59 \mathrm{~W} / \mathrm{cm}^{3}$. This value corresponds to a power peaking factor of 2.2 .

4.3. Burnup Distribution. Figure 8 depicts the radial distribution of fuel burnup in the core at the end of cycle (EOC). The fuel burnup levels can be categorized into three classes with the values in the ranges of $20-25 \%, 35-45 \%$, and $45-55 \%$ loss of ${ }^{235} \mathrm{U}$, respectively. The highest burnup of the FAs is $56.74 \%$ loss of ${ }^{235} \mathrm{U}$, which appears at location 5-4. In the burnup calculations, the fuel assembly is axially divided into five nodes with equal volumes. The highest burnup level in the axial nodes is about $66 \%$ loss of ${ }^{235} \mathrm{U}$. It can be seen from Figure 8 that the FA-2 assemblies have higher burnup levels of $49-56 \%$ loss of ${ }^{235} \mathrm{U}$. This is because the FA-2 assemblies were used together with the CRs during the reactor lifetime. The FAs with the burnup values less than $25 \%$ loss of ${ }^{235} \mathrm{U}$ are the fresh FAs loaded at the BOC of the core configuration. Since the locations of the CRs in the core can be changed from cycle to cycle upon the configuration design, the loading pattern for the next cycle can be determined with more flexible options.

4.4. Control Rod Reactivity Worths. The reactivity worths of the control rods and the shutdown margin have been evaluated and met requirements with condition when all safety CRs were withdrawn from the reactor core. The reactivity worths were calculated with the full insertion of the control rods. Meanwhile, the shutdown margin is defined when all ShR rods are fully inserted, SR1 is completely withdrawn, SR2 is fully inserted, and AR is at the middle of the core. Table 3 presents the reactivity worths of the nine control rods in the MPRR at the BOC. The reactivity worths of the SR1 and SR2 rods are $2051 \mathrm{pcm}$ and $2102 \mathrm{pcm}$, respectively. When the two SR rods are simultaneously fully inserted into the core, the total reactivity worth is $4629 \mathrm{pcm}$. Meanwhile, the reactivity worths of the ShR rods are within the range of 1156-2507 $\mathrm{pcm}$. One can see that the values of control rod worths are varied in a wide range depending on the positions of the ShR rods. The lowest control rod worth of $1156 \mathrm{pcm}$ is found at ShR1, while the highest value of $2507 \mathrm{pcm}$ is found at ShR3. The AR rod has the reactivity worth of $395 \mathrm{pcm}$, which is the smallest value compared to the other rods. It is because the AR rod is made of stainless steel, while other safety and shim rods are made of $\mathrm{B}_{4} \mathrm{C}$. The shutdown margin is about $-2330 \mathrm{pcm}$ corresponding to the $k_{\text {eff }}$ value of 0.97722 . 


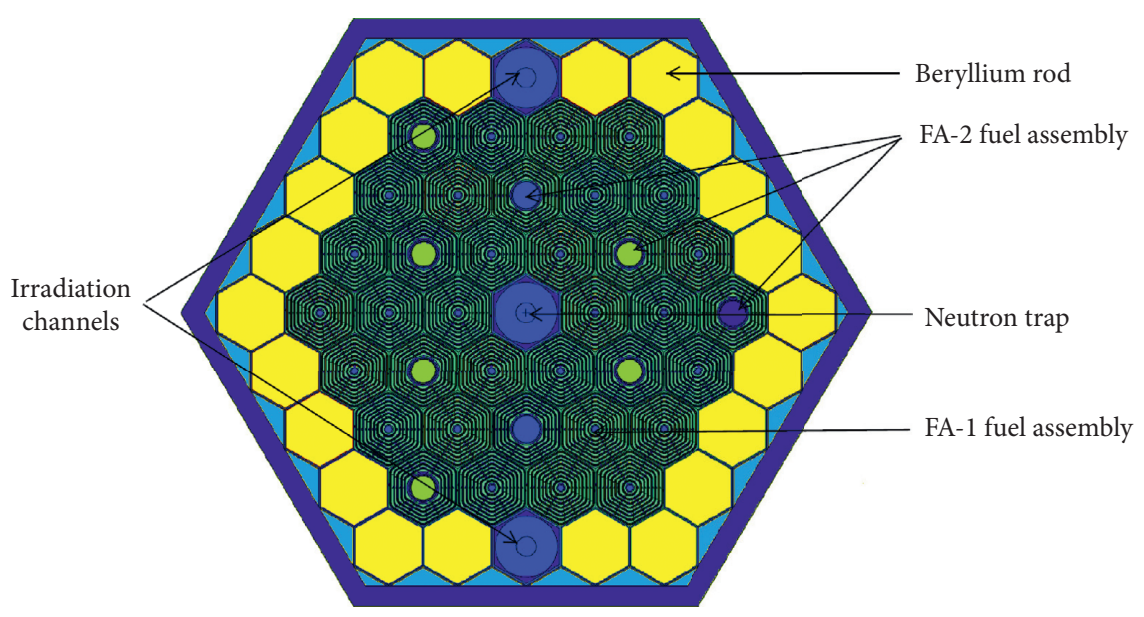

FIGURE 4: Configuration of the MPRR core with the power output of $10 \mathrm{MW}$.

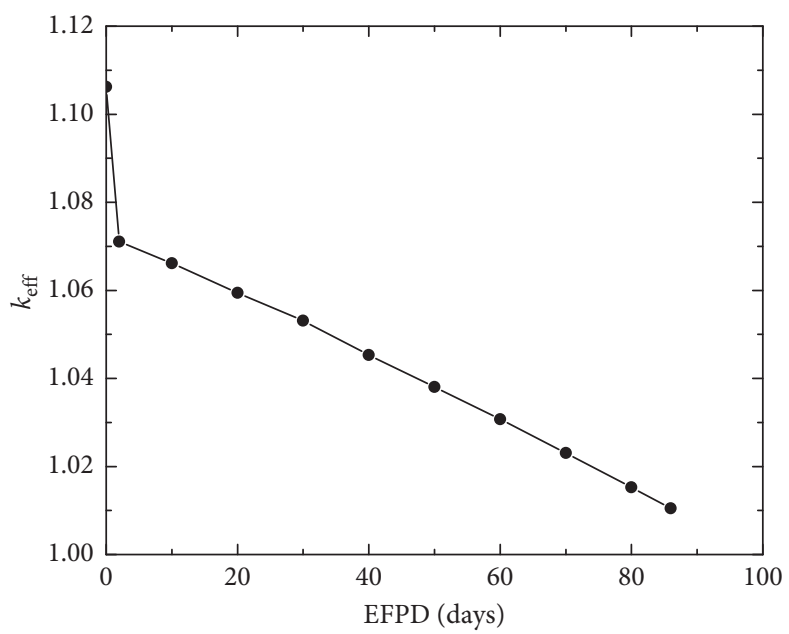

FIGURE 5: Burnup reactivity of the MPRR core.

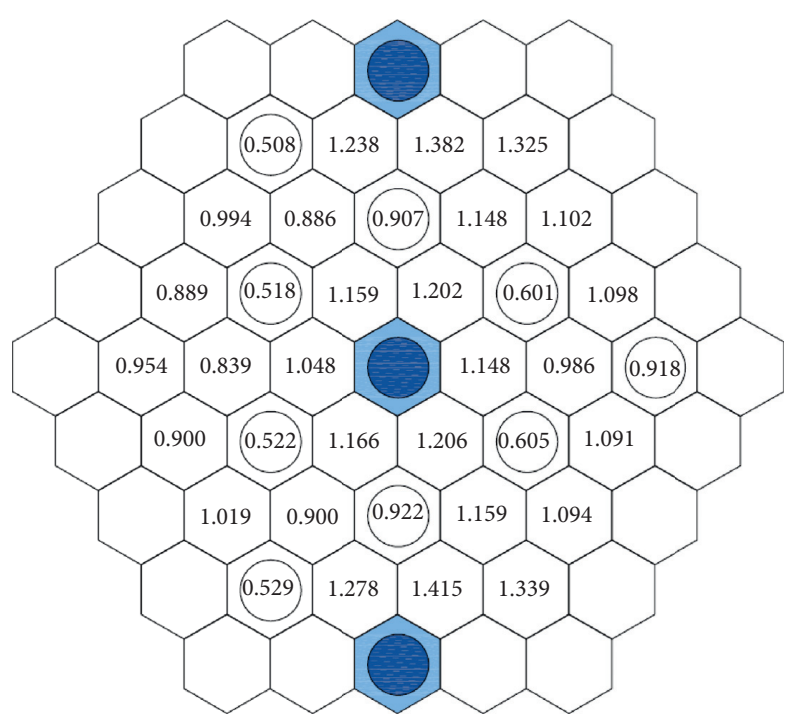

FIgURE 6: Radial relative power distribution of the MPRR core at the BOC. 
TABLE 2: Power rates in the fuel elements of the hottest fuel assembly. The fuel elements are numbered from outer to inner elements in the assembly.

\begin{tabular}{lccccccccc}
\hline Fuel element & FE 1 & FE 2 & FE3 & FE4 & FE5 & FE6 & FE7 & FE8 & Total \\
\hline Fuel volume $\left(\mathrm{cm}^{3}\right)$ & 92.481 & 82.114 & 71.747 & 61.38 & 51.013 & 40.646 & 30.278 & 18.868 & 448.527 \\
Power $(\mathrm{kW})$ & 106.21 & 80.28 & 61.79 & 47.67 & 36.69 & 27.84 & 20.24 & 12.78 & 393.49 \\
Average power density $\left(\mathrm{W} / \mathrm{cm}^{3}\right)$ & 1148.46 & 977.67 & 861.24 & 776.59 & 719.16 & 684.94 & 668.30 & 677.34 & - \\
\hline
\end{tabular}

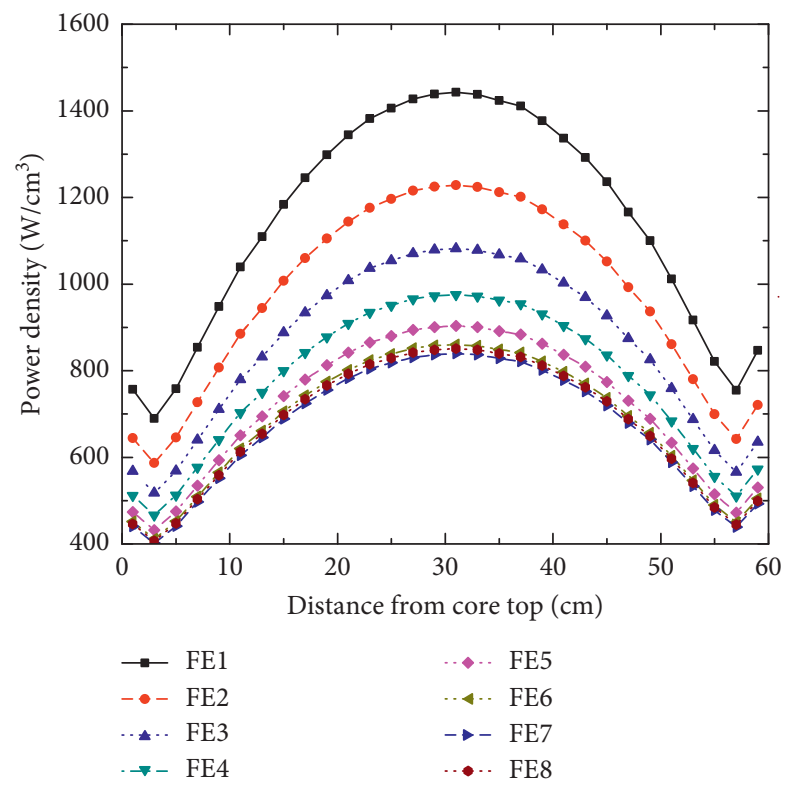

FIGURE 7: Axial power profile of the hottest channel in the hottest assembly located at cell 8-4. The fuel elements are numbered from outer to inner elements in the assembly.

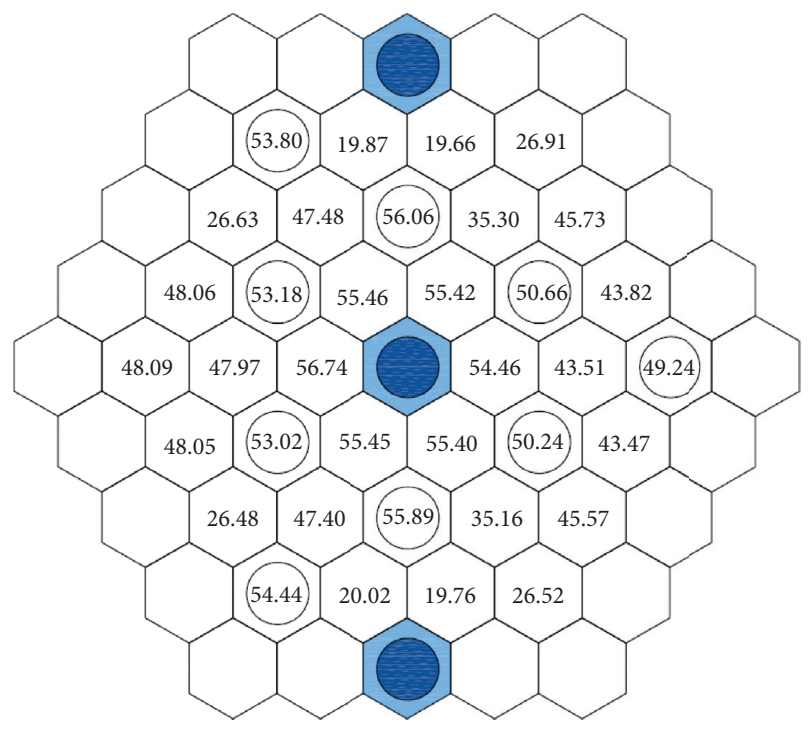

FIGURE 8: Burnup distribution in percent loss of ${ }^{235} \mathrm{U}$ at the EOC of the MPRR core.

4.5. Reactivity Coefficients. In order to evaluate the safety parameters of the new MPRR core, the feedback reactivity coefficients associated with the change of fuel and coolant temperatures and coolant void fraction at the BOC have
TABLE 3: Control rod worths in pcm unit of the MPRR core. Shutdown margin is determined at the condition that all ShR rods are fully inserted, SR1 is completely withdrawn, SR2 is fully inserted, and AR is at center line.

\begin{tabular}{lc}
\hline Control rod & $\mathrm{pcm}$ \\
\hline Safety rod SR1 & 2051 \\
Safety rod SR2 & 2102 \\
Two safety rods & 4629 \\
Automatic regulating rod (AR) & 395 \\
Shim rod ShR1 & 1156 \\
Shim rod ShR2 & 1996 \\
Shim rod ShR3 & 2507 \\
Shim rod ShR4 & 2056 \\
Shim rod ShR5 & 2498 \\
Shim rod ShR6 & 1298 \\
Shutdown margin & -2330 \\
\hline
\end{tabular}

been calculated. The temperature of the reflector (water and beryllium) was assumed to be equal to room temperature. To calculate the fuel temperature coefficient (FTC), the fuel temperature was assumed to vary in the range of 294-600 K. Then, the FTC at the BOC is obtained as $-2.467 \mathrm{pcm} / \mathrm{K}$. The coolant temperature coefficients (CTC) were evaluated in two ranges of coolant temperature of $294-350 \mathrm{~K}$ and $350-400 \mathrm{~K}$, where the linear change of the CTC is valid. It is 
found that the CTC values are about -11.594 and $-12.327 \mathrm{pcm} / \mathrm{K}$ in the two ranges of coolant temperatures, respectively. The void reactivity coefficient was also evaluated when the coolant in the active core was voided from 0 to $5 \%$. The void reactivity coefficient at the BOC is obtained as $-259.9 \mathrm{pcm}$ per one percent of coolant voided. The results show that the reactivity coefficients of the MPRR core are all negative. These values satisfy the design targets and the safety requirements recommended in IAEA guidelines $[24,25]$.

4.6. Neutron Fluxes at Irradiation Channels and Beam Tubes. Neutron fluxes in thermal energy range $(E<0.625 \mathrm{eV})$, epithermal range $(0.625 \mathrm{eV}-0.821 \mathrm{MeV})$, and fast energy range (0.821-10.0 MeV) at the vertical irradiation channels and the horizontal beam tubes have been evaluated at the BOC. Table 4 shows the average and maximum values of neutron fluxes in three groups at the vertical irradiation channels in the core and in the reflector. The highest thermal flux is found at the neutron trap with the average and maximum values of $2.02 \times 10^{14}$ and $2.54 \times 10^{14} \mathrm{n} \cdot \mathrm{cm}^{-2} \cdot \mathrm{s}^{-1}$, respectively. Thus, the neutron trap can be exploited for reactor fuel and material testing. The maximum thermal flux at the beryllium reflector is about $8.9 \times 10^{13} \mathrm{n} \cdot \mathrm{cm}^{-2} \cdot \mathrm{s}^{-1}$. The maximum thermal flux at the neutron cold source is $1.57 \times 10^{13} \mathrm{n} \cdot \mathrm{cm}^{-2} \cdot \mathrm{s}^{-1}$, while these values at the $\mathrm{SiD}$ positions are from $7.16 \times 10^{12}$ to $7.60 \times 10^{13} \mathrm{n} \cdot \mathrm{cm}^{-2} \cdot \mathrm{s}^{-1}$. Table 5 shows the neutron fluxes at the six horizontal beam tubes at the positions close to the core and near the outer reflector. The values of thermal fluxes at the horizontal beam tubes close to the core are in the range of $1.15-7.91 \times 10^{13} \mathrm{n} \cdot \mathrm{cm}^{-2} \cdot \mathrm{s}^{-1}$. It can be seen that the neutron fluxes at the irradiation channels of the newly designed MPRR meet the design targets as shown in Table 1 and the utilization requirements shown in $[1,2]$. The results imply that the neutron fluxes at the vertical irradiation channels and the horizontal neutron beam tubes are sufficient for the application purposes.

\section{Thermal Hydraulics Analysis}

Thermal hydraulics analysis at the steady state was performed for the hottest FA using the PLTEMP4.2 code to determine the safety parameters of the newly designed MPRR core. The hottest fuel assembly with the highest power rate of $393.49 \mathrm{~kW}$ is located at cell $8-4$ as shown in Figure 3 . The power rates and the axial power profiles of the FEs of the hottest assembly are displayed in Table 2 and Figure 7 , respectively. For ensuring the safety of cladding temperature, the maximum cladding surface temperature must be lower than $98^{\circ} \mathrm{C}$, and the ONBR must be greater than 1.3 as given in Table 1. In the thermal hydraulics analysis using the PLTEMP4.2 code, the built-in correlation for the VVR-KN fuel was used. The conditions of the inlet coolant are specified as follows: (1) the inlet coolant temperature is $45^{\circ} \mathrm{C}$, which is the maximum inlet temperature allowed during operation, (2) the inlet pressure is $0.135 \mathrm{MPa}$ at the core top, and (3) the coolant flow rate is
TABLE 4: Neutron fluxes $\left(\mathrm{n} \cdot \mathrm{cm}^{-2} \cdot \mathrm{s}^{-1}\right)$ at irradiation positions in the reactor core and reflector.

\begin{tabular}{|c|c|c|c|}
\hline Irradiation positions & Thermal & Epi-thermal & Fast \\
\hline \multicolumn{4}{|l|}{ Neutron trap } \\
\hline Average & $2.02 E+14^{\mathrm{a}}$ & $1.48 E+14$ & $5.89 E+13$ \\
\hline Maximum & $2.54 E+14$ & $1.82 E+14$ & $7.20 E+13$ \\
\hline \multicolumn{4}{|l|}{ Cold neutron source } \\
\hline Average & $1.23 E+13$ & $1.59 E+12$ & $4.02 E+11$ \\
\hline Maximum & $1.57 E+13$ & $2.07 E+12$ & $5.12 E+11$ \\
\hline \multicolumn{4}{|l|}{ SiD-1 } \\
\hline Average & $1.02 E+13$ & $6.99 E+11$ & $1.29 E+11$ \\
\hline Maximum & $1.30 E+13$ & $9.33 E+11$ & $1.65 E+11$ \\
\hline \multicolumn{4}{|l|}{ SiD-2 } \\
\hline Average & $5.65 E+12$ & $2.97 E+11$ & $6.29 E+10$ \\
\hline Maximum & $7.16 E+12$ & $3.94 E+11$ & $8.04 E+10$ \\
\hline \multicolumn{4}{|l|}{ SiD-3 } \\
\hline Average & $6.16 E+12$ & $3.04 E+11$ & $5.25 E+10$ \\
\hline Maximum & $7.82 E+12$ & $4.06 E+11$ & $6.70 E+10$ \\
\hline \multicolumn{4}{|l|}{ SiD-4 } \\
\hline Average & $1.01 E+13$ & $6.18 E+11$ & $1.03 E+11$ \\
\hline Maximum & $1.29 E+13$ & $8.31 E+11$ & $1.32 E+11$ \\
\hline \multicolumn{4}{|l|}{$\overline{\mathrm{B} 1}$} \\
\hline Average & $5.73 E+13$ & $1.03 E+13$ & $1.81 E+12$ \\
\hline Maximum & $7.15 E+13$ & $1.31 E+13$ & $2.29 E+12$ \\
\hline \multicolumn{4}{|l|}{$\mathrm{B} 2$} \\
\hline Average & $5.94 E+13$ & $1.12 E+13$ & $2.02 E+12$ \\
\hline Maximum & $7.60 E+13$ & $1.46 E+13$ & $2.58 E+12$ \\
\hline \multicolumn{4}{|l|}{$\overline{S 1}$} \\
\hline Average & $6.85 E+13$ & $1.52 E+13$ & $2.58 E+12$ \\
\hline Maximum & $8.70 E+13$ & $1.97 E+13$ & $3.30 E+12$ \\
\hline \multicolumn{4}{|l|}{$\mathrm{S} 2$} \\
\hline Average & $6.97 E+13$ & $1.58 E+13$ & $2.68 E+12$ \\
\hline Maximum & $8.90 E+13$ & $2.06 E+13$ & $3.42 E+12$ \\
\hline \multicolumn{4}{|l|}{ S3 } \\
\hline Average & $2.76 E+13$ & $2.35 E+12$ & $4.87 E+11$ \\
\hline Maximum & $3.53 E+13$ & $3.15 E+12$ & $6.20 E+11$ \\
\hline \multicolumn{4}{|l|}{ S4 } \\
\hline Average & $2.85 E+13$ & $2.66 E+12$ & $5.56 E+11$ \\
\hline Maximum & $3.62 E+13$ & $3.51 E+12$ & $7.17 E+11$ \\
\hline \multicolumn{4}{|l|}{$\overline{\mathrm{S} 5}$} \\
\hline Average & $2.64 E+13$ & $2.40 E+12$ & $5.09 E+11$ \\
\hline Maximum & $3.33 E+13$ & $3.16 E+12$ & $6.57 E+11$ \\
\hline \multicolumn{4}{|l|}{$\overline{S 6}$} \\
\hline Average & $1.55 E+13$ & $7.99 E+11$ & $1.40 E+11$ \\
\hline Maximum & $2.08 E+13$ & $1.27 E+12$ & $1.85 E+11$ \\
\hline \multicolumn{4}{|l|}{ S7 } \\
\hline Average & $1.38 E+13$ & $7.09 E+11$ & $1.60 E+11$ \\
\hline Maximum & $1.76 E+13$ & $9.68 E+11$ & $2.08 E+11$ \\
\hline \multicolumn{4}{|l|}{$\overline{S 8}$} \\
\hline Average & $1.28 E+13$ & $6.91 E+11$ & $1.64 E+11$ \\
\hline Maximum & $1.62 E+13$ & $9.15 E+11$ & $2.10 E+11$ \\
\hline \multicolumn{4}{|l|}{ S9 } \\
\hline Average & $1.19 E+13$ & $6.43 E+11$ & $1.46 E+11$ \\
\hline Maximum & $1.50 E+13$ & $8.58 E+11$ & $1.89 E+11$ \\
\hline
\end{tabular}

${ }^{\mathrm{a}}$ Read as $2.02 \times 10^{14}$.

$5.58 \mathrm{~kg} / \mathrm{s}$. The temperatures of fuel, cladding surface, and coolant and the ONBR and DNBR parameters at a steady state have been evaluated. 
TABLE 5: Neutron fluxes $\left(\mathrm{n} \cdot \mathrm{cm}^{-2} \cdot \mathrm{s}^{-1}\right)$ at the horizontal beam tubes.

\begin{tabular}{|c|c|c|c|c|c|c|}
\hline \multirow{2}{*}{ Beam port } & \multicolumn{3}{|c|}{ At position close to the core } & \multicolumn{3}{|c|}{ At position near reflector } \\
\hline & Thermal & Epi-thermal & Fast & Thermal & Epi-thermal & Fast \\
\hline HBT1-1 & $7.91 E+13^{\mathrm{a}}$ & $2.74 E+13$ & $3.19 E+12$ & $1.26 E+13$ & $9.22 E+12$ & $6.50 E+10$ \\
\hline HBT1-2 & $7.93 E+13$ & $2.78 E+13$ & $3.38 E+12$ & $1.26 E+13$ & $9.44 E+12$ & $7.12 E+10$ \\
\hline HBT2-1 & $4.46 E+13$ & $1.51 E+13$ & $1.97 E+12$ & $1.92 E+13$ & $1.39 E+12$ & $9.61 E+10$ \\
\hline HBT2-2 & $4.34 E+13$ & $1.47 E+13$ & $1.88 E+12$ & $1.85 E+13$ & $1.36 E+12$ & $9.58 E+10$ \\
\hline HBT3-1 & $1.16 E+13$ & $6.10 E+12$ & $1.08 E+12$ & $9.46 E+12$ & $1.94 E+11$ & $3.27 E+10$ \\
\hline HBT3-2 & $1.15 E+13$ & $5.98 E+12$ & $1.05 E+12$ & $9.40 E+12$ & $1.91 E+11$ & $3.23 E+10$ \\
\hline
\end{tabular}

${ }^{\mathrm{a}} \operatorname{Read}$ as $7.91 \times 10^{13}$.

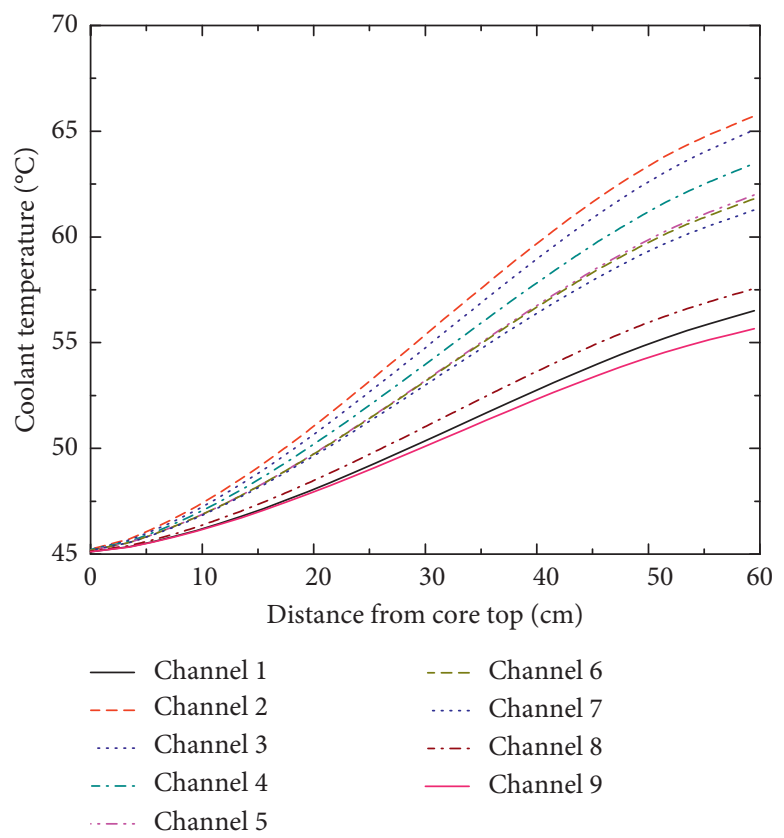

Figure 9: Axial profile of coolant temperature in the channels of the hottest fuel assembly. The channels are numbered from outer to inner channels of the FA.

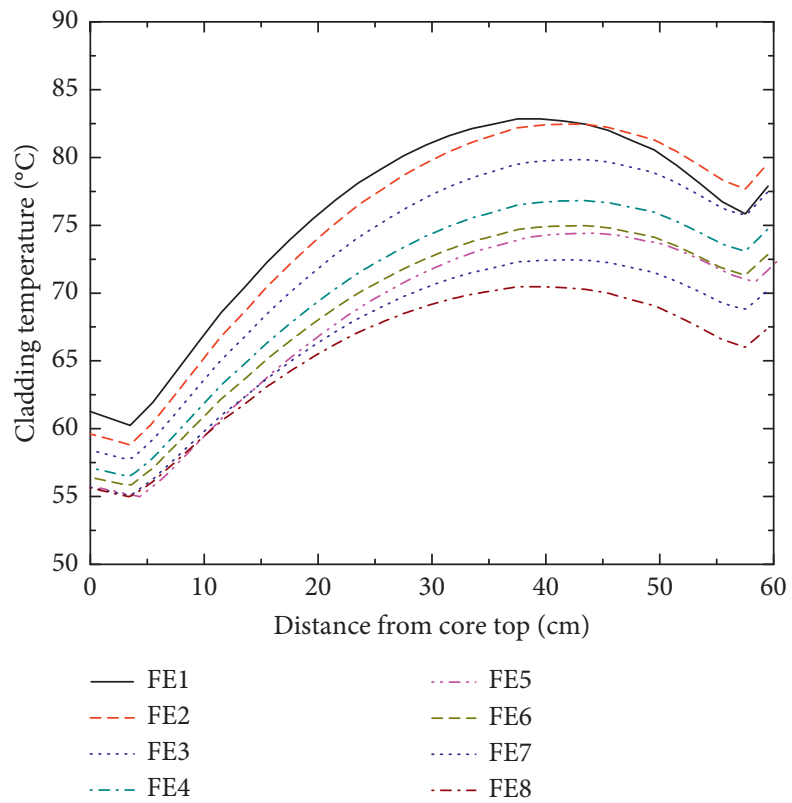

FIGURE 10: Axial profile of cladding temperature of the FEs in the hottest assembly. The FEs are numbered from outer to inner FEs in the FA. 
Figures 9 and 10 display the axial profiles of the coolant and cladding temperatures in the hottest fuel assembly in the case without the application of a hotspot factor. One can see that the highest coolant temperature and the maximum cladding temperature are of $66^{\circ} \mathrm{C}$ and $83^{\circ} \mathrm{C}$, respectively. The values are lower than the safety limits of the design. The minimum values of the ONBR and the DNBR are 1.80 and 7.02 , respectively, which satisfy the safety limits. The results of the thermal hydraulics analysis at the steady state have confirmed that the new design of the MPRR core meets the safety criteria in the IAEA guidelines [24, 25].

\section{Conclusions}

Conceptual design of a 10 MW MPRR core using the VVR$\mathrm{KN}$ fuel has been conducted using the REBUS-MCNP6 linkage code and the ENDF/B-VII.0 data library. The core is loaded with 36 LEU fuel assemblies: 27 standard fuel assemblies and 9 control fuel assemblies. The cycle length is 86 effective full-power days with the excess reactivity of 9600 and $1039 \mathrm{pcm}$ at the $\mathrm{BOC}$ and the EOC, respectively. The highest discharged burnup of the fuel assembly is $56.74 \%$ loss of ${ }^{235} \mathrm{U}$. The highest power rate per assembly is $393.49 \mathrm{~kW}$. The maximum power density per fuel volume is about $1442.59 \mathrm{~W} / \mathrm{cm}^{3}$, which corresponds to a power peaking factor of 2.2. Feedback reactivity coefficients regarding the change of fuel and coolant temperatures and coolant void fraction are all negative. The reactivity worths of the nine control rods ensure the safe operation of the core and provide sufficient shutdown margin. The results show that the neutronics performance of the newly designed MPRR core meets the design targets. Thermal hydraulics analysis at the steady state has been performed for the hottest fuel assembly using the PLTEMP4.2 code. The maximum coolant and cladding temperatures at the hottest channel are $66.0^{\circ} \mathrm{C}$ and $83.0^{\circ} \mathrm{C}$, respectively, without the application of a hotspot factor. The minimum ONBR and DNBR are about 1.80 and 7.02, respectively. These values satisfy the safety limits. For the purposes of application, the neutron fluxes at the vertical and horizontal irradiation channels have been analyzed. The maximum thermal neutron flux of $2.5 \times 10^{14} \mathrm{n} \cdot \mathrm{cm}^{-2} \cdot \mathrm{s}^{-1}$ is obtained at the neutron trap located in the core center, whereas this value at the beryllium reflector is about $8.9 \times 10^{13} \mathrm{n} \cdot \mathrm{cm}^{-2} \cdot \mathrm{s}^{-1}$.

\section{Data Availability}

Data will be made available upon request.

\section{Conflicts of Interest}

The authors declare that they have no conflicts of interest regarding the publication of this paper.

\section{Acknowledgments}

The authors are grateful to the administrative staffs of VINATOM and DNRI for their kind support. The staffs at Reactor Physics and Engineering Department of DNRI are acknowledged for their valuable technical discussions.
Collaborations with the staffs of Argonne National Lab. and Institute of Nuclear Physics of Kazakhstan are greatly appreciated. This research was supported by Ministry of Science and Technology of Vietnam under Grant no. DTDL.CN-50/15.

\section{References}

[1] IAEA (International Atomic Energy Agency), "The applications of research reactors," IAEA, Vienna, Austria, IAEATECDOC-1234, 2001.

[2] IAEA (International Atomic Energy Agency), "Applications of research reactors," IAEA, Vienna, Austria, IAEA Nuclear Energy Series No. NP-T-5.3, 2014.

[3] G. Phan, H. N. Tran, K. C. Nguyen et al., "Comparative analysis of the Dalat nuclear research reactor with HEU fuel using SRAC and MCNP5," Science and Technology of Nuclear Installations, vol. 2017, Article ID 2615409, 10 pages, 2017.

[4] Q. B. Do, G. T. T. Phan, K. C. Nguyen, Q. H. Ngo, and H. N. Tran, "Criticality and control rod worth analysis of the DNRR research reactor using the SRAC and MCNP5 codes," Nuclear Engineering and Design, vol. 343, pp. 197-209, 2019.

[5] V. K. Raina, K. Sasidharan, S. Sengupta, and T. Singh, "Multipurpose research reactor," Nuclear Engineering and Design, vol. 236, pp. 770-783, 2006.

[6] F. E. Teruel and Rizwan-uddin, "An innovative research reactor design," Nuclear Engineering and Design, vol. 239, pp. 395-407, 2009.

[7] C. G. Seo and N. Z. Cho, "A core design concept for multipurpose research reactors," Nuclear Engineering and Design, vol. 252, pp. 34-41, 2012.

[8] C. G. Seo, H. T. Chae, B. C. Lee, B. J. Jun, and I. C. Lim, "Conceptual nuclear design of the kijang research reactor," in Proceedings of the Transactions of the RRFM-2013 European Research Reactor Conference, pp. 491-496, Saint Petersburg, Russia, April 2013.

[9] S. Kim, "The OPAL (open pool Australian light-water) reactor in Australia," Nuclear Engineering and Technology, vol. 38, no. 5, pp. 443-448, 2006.

[10] E. Villarino and A. Doval, "INVAP's research reactor designs," Science and Technology of Nuclear Installations, vol. 2011, Article ID 490391, 6 pages, 2011.

[11] P. Cantero, P. Ramirez, F. Brollo et al., "Key technical characteristics related to the design of the RA-10 Multipurpose Research Reactor," in Proceedings of European Research Reactor Conference (RRFM/IGORR-2016), pp. 683-693, Berlin, Germany, March 2016.

[12] X. Lin, R. Henkelmann, A. Turler, H. Gerstenberg, and F. D. Corte, "Neutron flux parameters at irradiation positions in the new research reactor FRM-II," Nuclear Instruments and Methods in Physics Research Section A: Accelerators, Spectrometers, Detectors and Associated Equipment, vol. 564, no. 2, pp. 641-644, 2006.

[13] H. Kim, H. R. Kim, K. H. Lee, and J. B. Lee, "Design characteristics and startup tests of HANARO," Journal of Nuclear Science and Technology, vol. 33, no. 7, pp. 527-538, 1996.

[14] K. N. Choo, M. S. Cho, S. W. Yang, and S. J. Park, "Contribution of HANARO irradiation technologies to national nuclear R\&D," Nuclear Engineering and Technology, vol. 46, no. 4, pp. 501-512, 2014.

[15] D. Campolina, A. C. L. da Costa, E. P. Andrade, A. A. C. Santos, and V. Vasconcelos, "Neutronic analysis of the fuel loaded irradiation loop device of the RMB 
Multipurpose Brazilian Reactor," Progress in Nuclear Energy, vol. 104, pp. 109-116, 2018.

[16] M. K. Jaradat, V. Radulovi, C. J. Park, L. Snoj, and S. M. Alkhafaji, "Verification of MCNP6 model of the Jordan Research and Training Reactor (JRTR) for calculations of neutronic parameters," Annals of Nuclear Energy, vol. 96, pp. 96-103, 2016.

[17] N. A. Hanan and P. L. Garner, "Neutronic, steady state and transient analyses for the kazakhstan WWR-K reactor with LEU fuel: ANL independent verification results," ANL/RTR/ TM-15/7, 120766, Argonne National Laboratory, Lemont, IL, USA, 2015.

[18] I. T. Tretiyakov, S. A. Sokolov, V. I. Trushkin et al., "Project development for promising pool-type Research Reactors," in Proceedings of the Transactions of the RRFM-2013 European Research Reactor Conference, pp. 505-510, Saint Petersburg, Russia, April 2013.

[19] ORNL, MCNP6.1/MCNP5/MCNPX, Monte Carlo N-Particle Transport Code System Including MCNP6.1, MCNP5-1.60, MCNPX-2.7.0 and Data Libraries, Contributed by Los Alamos National Laboratory, RSICC Computer Code Collection, Oak Ridge National Laboratory, Oak Ridge, TN, USA, 2013.

[20] M. B. Chadwick, P. Oblozinsky, M. Herman et al., "ENDF/BVII.0: next generation evaluated nuclear data library for nuclear science and technology," Nuclear Data Sheets, vol. 107, pp. 2931-3060, 2006.

[21] N. A. Hanan, A. P. Olson, R. B. Pond, and J. E. Matos, "A Monte Carlo burnup code linking MCNP and REBUS," in Proceedings of the 20th International Meeting on Reduced Enrichment for Research and Test Reactors, RERTR 1998, Sao Paulo, Brazil, October 1998.

[22] J. G. Stevens, “The REBUS-MCNP linkage," Argonne National Laboratory, Lemont, IL, USA, ANL/RERTR/TM-08-04, 2008.

[23] A. P. Olson and M. Kalimullah, "A users guide to the PLTEMP/ANL code," Argonne National Laboratory, Lemont, IL, USA, ANL/RERTR/TM-11-22 Version 4.2, 2015.

[24] IAEA (International Atomic Energy Agency), "Code on the safety of nuclear research reactors: design," IAEA, Vienna, Austria, Safety Series No. 35-S1, 1992.

[25] IAEA (International Atomic Energy Agency), "Safety of Research Reactors. IAEA Safety Standards," IAEA, Vienna, Austria, Specific Safety Requirements No. SSR-3, 2016. 